\title{
EJACULATION AND EJACULATE CHARACTERISTICS OF ANGONI (SHORT HORN ZEBU) BULLS
}

\author{
G. IGBOELI AND A. M. RAKHA \\ National Council for Scientific Research, \\ P.O. Box 49, Chilanga, Zambia
}

(Received 7th September 1970, revised 1st December 1970)

\begin{abstract}
Summary. Although it was generally believed that Angoni bulls (Central African Zebu) would not serve the artificial vagina, a total of 229 ejaculates were collected from ten bulls during a 6-week period. Four ejaculates were collected each week, two after 4 days' rest and two after 3 days' rest following a limited teasing procedure.

Ejaculate volume was significantly higher in the first than in the second ejaculates and higher after 4 than after 3 days' rest. The percentage of progessively motile spermatozoa in the ejaculates did not differ significantly. Over $70 \%$ of the ejaculated spermatozoa were morphologically normal. The mean total number of spermatozoa/ ejaculate and sperm output/week averaged $5.6 \times 10^{9}$ and $22.6 \times 10^{9}$, respectively.
\end{abstract}

\section{INTRODUCTION}

The Angoni breed of cattle is one of the predominant types of indigenous breeds in Central Africa and is related to the small East African Zebu breed (Mason \& Maule, 1960). The lack of basic information on their pattern of reproduction is an obstacle to any programme aimed at improving their productivity.

The present study was conducted to evaluate the ejaculate characteristics of Angoni bulls, and to assess the results in terms of their importance to the problem of infertility.

In recent years, artificial insemination (AI) has been applied on both local and exotic breeds in Central Africa, using imported semen. It is anticipated that this practice will expand and semen from native bulls will be used.

\section{MATERIALS AND METHODS}

Twelve Angoni bulls, 3 to 4 years old, were trained to serve the artificial vagina using cows on heat, non-oestrous cows and intact bulls. Following a 4-week training period, ejaculates were collected from ten of these bulls four times each week (two after 4 , and two after 3 days' rest) for a 6 -week period, starting early in February (experimental period). This period coincides with the best grazing conditions and approximately with the time of year when cows are mated in Zambia. 
Each bull was allowed one false mount and then semen was collected at the second mount, all within a 5-min teasing period. Approximately $60 \mathrm{~min}$ later, a second ejaculate was obtained following the same teasing procedures.

Each ejaculate was examined for volume, percentage of progessively motile spermatozoa and sperm concentration which was determined photometrically (Salisbury, Beck, Elliott \& Willett, 1943). The pH was determined by use of a bromo-thymol blue indicator. Duplicate smears stained with nigrosin-eosin were prepared to determine the numbers of live-dead and morphologically normal spermatozoa. A total of one hundred spermatozoa/smear were classified in each case. Spermatozoa bearing protoplasmic droplets were also determined.

The experiment was considered a $10 \times 6 \times 2 \times 2$ factorial with bulls (10), weeks (6), rest interval (2), and order of collection (2) considered random. Missing values were estimated using standard missing plot techniques.

\section{RESULTS}

\section{Libido and ejaculation}

Semen was collected satisfactorily from ten out of twelve bulls within 1 month of training, and from approximately half of these within the 1st week. The two bulls which did not ejaculate within the 4-week training period were excluded.

During training, it was observed that bulls on lead would not attempt to mount teasers. Bulls showed sexual interest only in cows on heat and it took considerable time to train them to mount other animals, including bulls. After this stage, no differences were observed in their preference for teasers.

Of the 240 ejaculates expected during the experimental period, a total of 229 were collected. Bulls were more sexually interested in the teasers after 4 days' rest than after 3 days' rest.

\section{Semen quality}

Results are summarized in Table 1 , and the analysis of variance in Table 2.

The volume of the first ejaculate was significantly higher than the second $(P<0.01)$ and was higher after 4 days' than after 3 days' rest $(P<0.001)$. There was no significant interaction between the number of days of rest and the order of ejaculates since first ejaculates after 4 or after 3 days' rest tended to be higher than the corresponding means of the second ejaculates. Ejaculate volume was higher in the 1st week compared to the other weeks, but did not vary thereafter. Bull differences were very highly significant $(P<0 \cdot 01)$.

The percentages of progressively motile spermatozoa were not significantly different between first and second ejaculates or between ejaculates collected after 3 or 4 days' rest $(P>0.05)$; bull differences were significant $(P<0.05)$.

Sperm concentration was higher in the first than in the second ejaculate $(P<0.01)$, though no differences were found between the 3- and 4-day rest periods. Total spermatozoa/ejaculate and the total sperm output/week averaged $5.66 \times 10^{9}$ and $22.62 \times 10^{9}$, respectively. The total output of motile spermatozoa/ bull/week averaged $13.45 \times 10^{9}$.

In terms of morphologically normal spermatozoa, apart from differences 


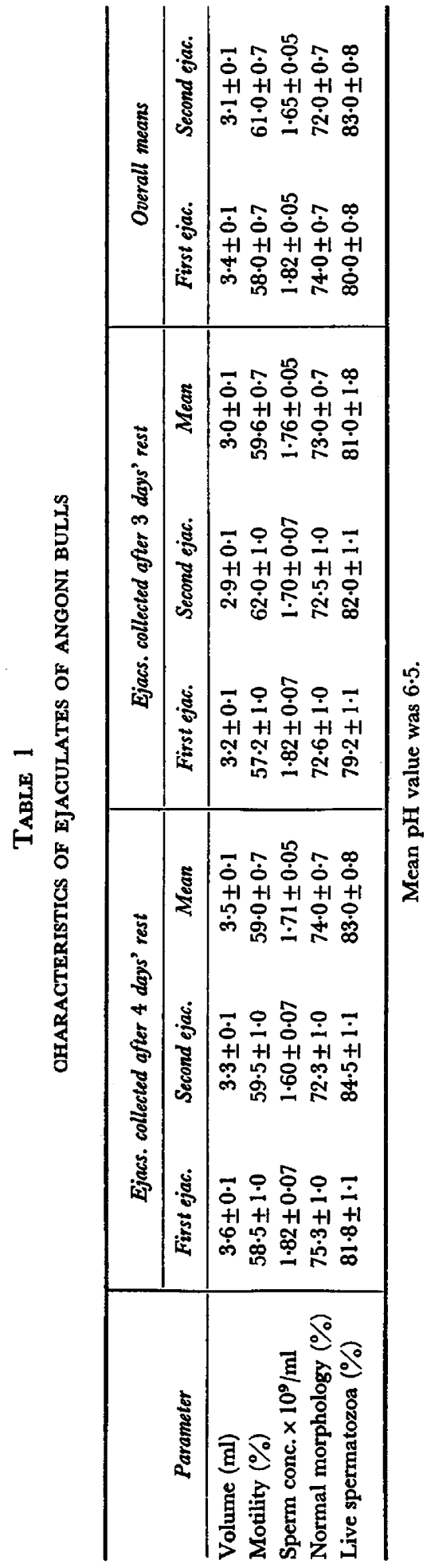


between bulls $(P<0.01)$ and between weeks $(P<0.01)$, no other differences were observed. Over $70 \%$ of the ejaculated spermatozoa were morphologically normal. Spermatozoa with absent or coiled tails were the predominant types of abnormalities observed. Less than $2 \%$ of all spermatozoa retained their protoplasmic droplets and over $80 \%$ of the ejaculated spermatozoa were live.

Only a slight variation was observed in the hydrogen ion concentration of the ejaculates which had a mean value of 6.5 .

TABle 2

ANALYSES OF VARIANCE

\begin{tabular}{|c|c|c|c|c|c|c|}
\hline \multirow[b]{2}{*}{ Source } & \multirow[b]{2}{*}{ d.f. } & \multicolumn{5}{|c|}{ Mean squares } \\
\hline & & $\begin{array}{c}\text { Volume } \\
(m l)\end{array}$ & $\begin{array}{c}\text { Motility } \\
(\%)\end{array}$ & $\begin{array}{c}\text { Sperm } \\
\text { count } \\
10^{9}\end{array}$ & $\begin{array}{c}\text { Normal } \\
\text { morphology } \\
(\%)\end{array}$ & $\begin{array}{c}\text { Viability } \\
(\%)\end{array}$ \\
\hline $\begin{array}{l}\text { Bulls (B) } \\
\text { Weeks (W) } \\
\text { Ejaculates (E) } \\
\text { Interval }(I) \\
\mathbf{B} \times \mathbf{W} \\
\mathbf{B} \times \mathbf{E} \\
\mathbf{B} \times \mathbf{I} \\
W \times \mathbf{E} \\
W \times \mathbf{I} \\
\mathbf{E} \times \mathbf{I} \\
\text { Error }\end{array}$ & $\begin{array}{r}9 \\
5 \\
1 \\
1 \\
45 \\
9 \\
9 \\
5 \\
5 \\
1 \\
138\end{array}$ & $\begin{array}{c}6 \cdot 67^{* * *} \\
2 \cdot 84^{* *} \\
6 \cdot 08^{* * *} \\
10 \cdot 67 * * * \\
0.82 \\
0.38 \\
0.33 \\
0.37 \\
0.97 \\
0.11 \\
0.87\end{array}$ & $\begin{array}{c}385 \cdot 32 \\
217 \cdot 42 \\
510 \cdot 42 \\
20 \cdot 42 \\
118 \cdot 90^{* *} \\
65 \cdot 97 \\
116 \cdot 71^{*} \\
77 \cdot 42 \\
23 \cdot 42 \\
220 \cdot 41^{*} \\
56 \cdot 34\end{array}$ & $\begin{array}{l}2 \cdot 0034 * * * \\
0 \cdot 2443 \\
1 \cdot 7672 * * \\
0 \cdot 1403 \\
0 \cdot 2867 \\
0 \cdot 3787 \\
0 \cdot 1585 \\
0 \cdot 3999 \\
0 \cdot 2804 \\
0 \cdot 1575 \\
0 \cdot 2536\end{array}$ & $\begin{array}{l}183^{* *} \\
224 * * \\
145 \\
100 \\
53 \\
35 \\
60 \\
51 \\
96 \\
125 \\
56\end{array}$ & $\begin{array}{c}103 \\
300^{* *} \\
448^{*} \\
380 \\
93 \\
57 \\
174^{*} \\
61 \\
43 \\
0 \\
78\end{array}$ \\
\hline \multicolumn{2}{|l|}{$\begin{array}{l}\text { S.D. } \\
\text { Mean }\end{array}$} & $\begin{array}{c} \pm 0.931 \\
3.26\end{array}$ & $\begin{array}{c} \pm 7 \cdot 51 \\
59 \cdot 3\end{array}$ & $\begin{array}{c} \pm 0.504 \\
1.73\end{array}$ & $\begin{array}{l} \pm 7 \cdot 48 \\
73 \cdot 2\end{array}$ & $\begin{array}{l} \pm 8.83 \\
81.9\end{array}$ \\
\hline \multicolumn{2}{|c|}{ Coeff. of variability } & $28.6 \%$ & $12 \cdot 6 \%$ & $29 \cdot 0 \%$ & $10.2 \%$ & $10.8 \%$ \\
\hline
\end{tabular}

Although data on motility, sperm count and viability were recorded in percentages, these were not transformed before analysis as the percentage values were well within the 30 to $70 \%$ range.

$$
* P=0.05 ; * * P=0.01 ; * * P=0.001 \text {. }
$$

\section{DISGUSSION}

Bulls in the tropics are considered to be under temperature stress and, as such, they would be expected to produce a poorer quality semen (Casady, Myers \& Legates, 1953; Dutt, 1960; Skinner \& Louw, 1966). The present results do not support this view and indicate that the semen of the indigenous bulls shows good motility, viability and morphology. Since these parameters may not predict fertility precisely (Bishop, 1955; Bratton, Foote, Henderson, Musgrave, Dunbar, Dunn \& Beardsley, 1956), experiments planned to yield information on conception rate are being undertaken.

A high positive correlation has been reported between testis size and sperm production (Willett \& Ohms, 1957; Hupp, Austin, Parish \& Murphree, 1962; Hahn, Foote \& Seidel, 1969). In general, the testes of local bulls are much smaller than those of exotic breeds (Igboeli \& Rakha, 1971), and this is reflected in the mean ejaculate volume and total sperm output per ejaculate or per week. Moreover, the reduced libido and the difference in volume and sperm concentration between ejaculates obtained after 3 days' and 4 days' rest would tend to suggest that collection of semen more than four times a week 
might strain the bulls (Singh \& Prabhu, 1963). It would be interesting, therefore, to investigate several teasing and collection regimens in order to determine the optimal collection schedule for these bulls. The sperm reserves in Angoni bulls have been studied (Igboeli \& Rakha, 1971) but further work is required to determine the contribution of each accessory gland to the ejaculate. With the fairly high concentration of spermatozoa in the ejaculate in relation to the size of the testes, a study of the kinetics of spermatogenesis in these bulls will be desirable.

On average, each bull produced a total of $13.45 \times 10^{9}$ motile spermatozoa/ week, which, under optimal conditions of storage, would be adequate to inseminate over 1000 cows. Due to the limited sexual preparation (5-min teasing period and one false mount) applied during this study, a higher sperm output would be anticipated by allowing two or more false mounts and a longer teasing period (Collins, Bratton \& Henderson, 1951; Hafs, Knisely \& Desjardins, 1962).

A high proportion of the variability observed was due to bull differences, suggesting that several of these traits would respond to selection.

\section{AGKNOWLEDGMENTS}

The authors are grateful to Mr Dutta-Roy for the statistical analysis, and to $\mathrm{Mr}$ Y. Kapyanga and Mr J. Nguluwe for technical assistance.

Parts of this material were presented at the Annual Meeting of the Society for the Study of Fertility, Liverpool, July 1970.

\section{REFERENCES}

Bisнop, M. W. H. (1955) Inter-relationships of semen characteristics. Stud. Fert. 7, 48.

Bratton, R. W., Foote, R. H., Henderson, G. R., Musgrave, S. D., Dunbar, R. S., JR, Dunn, H. D. \& BEARDSLEY, J. P. (1956) The relative usefulness of combinations of laboratory tests for predicting fertility of bovine semen. 7. Dairy Sci. 39, 1542.

Gasady, R. B., MYers, R. M. \& Legates, J. E. (1953) The effects of exposure to high ambient tempera ture on spermatogenesis in the dairy bull. 7. Dairy Sci. 36, 14.

Collins, W. J., Bratton, R. W. \& Henderson, G. R. (1951) The relationship of semen production to sexual excitement of dairy bulls. F. Dairy Sci. 34, 224.

Dutr, R. H. (1960) Temperature and light as factors in reproduction among farm animals. F. Dairy Sci. (Suppl.), 43, 123.

Hafs, H. D., Knisely, R. C. \& Desjardins, G. (1962) Sperm output of dairy bulls with varying degrees of sexual preparation. F. Dairy Sci. 45, 788.

HAhN, J., Foote, R. H. \& Semel, G. E., JR (1969) Testicular growth and related sperm output in dairy bulls. F. Anim. Sci. 29, 41.

Hupp, E. W., Austin, J. W., Parish, N. R. \& Murphree, R. L. (1962) Sperm production of Hereford bulls at different intensities of collection. F. Anim. Sci. 21, 272.

Igrozli, G. \& RAkнA, A. M. (1971) Gonadal and extragonadal sperm reserves of indigenous Gentral African bulls. F. Reprod. Fert. 25, 107.

Mason, I. L. \& MAULE, J. P. (1960) The indigenous livestock of eastern and southern Africa, p. 72. Commonwealth Agricultural Bureaux, Edinburgh.

Salisbury, G. W., Beck, G. H., Elliott, F. I. \& Willett, E. L. (1943) Rapid methods for estimating the number of spermatozoa in bull semen. F. Dairy Sci. 26, 69 .

Singh, G., \& Prabhu, S. S. (1963) Effect of frequency of collection upon reaction time and semen quality in Kumauni hill bulls. F. Anim. Morph. Physiol. 10, 107.

Skinner, J. D. \& Louw, G. N. (1966) Heat stress and spermatogenesis in Bos indicus and Bos taurus cattle. 7. appl. Physiol. 21, 1784.

Willett, E. L. \& OHMs, J. I. (1957) Measurement of testicular size and its relation to production of spermatozoa by bulls. F. Dairy Sci. 40, 1959. 